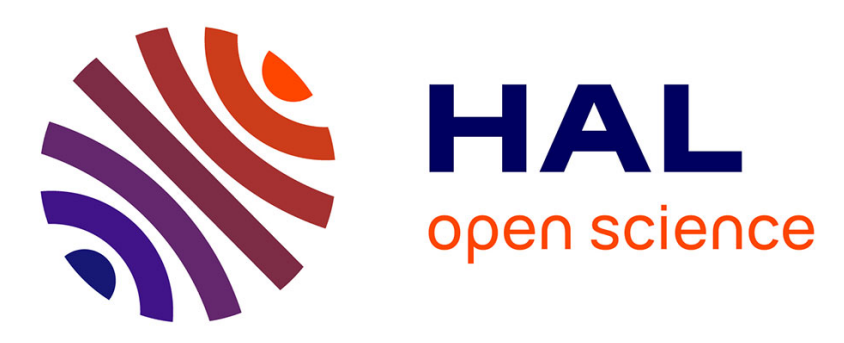

\title{
Palladium-Catalyzed C-H Bond Functionalization of 6,6-Diphenylfulvenes: An Easier Access to C1-Arylated and C1,C4-Diarylated Fulvenes
}

Mariem Brahim, Hamed Ben Ammar, Vincent Dorcet, Jean-François Soulé, Henri Doucet

\section{To cite this version:}

Mariem Brahim, Hamed Ben Ammar, Vincent Dorcet, Jean-François Soulé, Henri Doucet. Palladium-Catalyzed C-H Bond Functionalization of 6,6-Diphenylfulvenes: An Easier Access to C1-Arylated and C1,C4-Diarylated Fulvenes. Organic Letters, 2017, 19 (10), pp.2584-2587. 10.1021/acs.orglett.7b00900 . hal-01533330

\section{HAL Id: hal-01533330 \\ https://hal-univ-rennes1.archives-ouvertes.fr/hal-01533330}

Submitted on 12 Oct 2017

HAL is a multi-disciplinary open access archive for the deposit and dissemination of scientific research documents, whether they are published or not. The documents may come from teaching and research institutions in France or abroad, or from public or private research centers.
L'archive ouverte pluridisciplinaire HAL, est destinée au dépôt et à la diffusion de documents scientifiques de niveau recherche, publiés ou non, émanant des établissements d'enseignement et de recherche français ou étrangers, des laboratoires publics ou privés. 


\title{
Palladium-catalysed C-H bond functionalisation of 6,6- diphenylfulvenes: an easier access to C1-arylated and C1,C4- diarylated fulvenes
}

\author{
Mariem Brahim, ${ }^{[\mathrm{a}, \mathrm{b}]}$ Hamed Ben Ammar, ${ }^{*[\mathrm{~b}]}$ Vincent Dorcet, ${ }^{[\mathrm{a}]}$ Jean-François Soulé, ${ }^{[\mathrm{a}]}$ and Henri Dou- \\ cet*[a] $^{*}$
}

[a] Institut des Sciences Chimiques de Rennes UMR 6226 CNRS-Université de Rennes 1 "Organométalliques: Matériaux et Catalyse", 35042 Rennes Cedex, E-mail: jean-francois.soule@univ-rennes1.fr; henri.doucet@univ-rennes1.fr

[b] Laboratoire de Synthèse Organique Asymétrique et Catalyse Homogène, (UR 11ES56), Université de Monastir, Faculté des Sciences de Monastir, avenue de l'environnement, Monastir 5000, Tunisia.

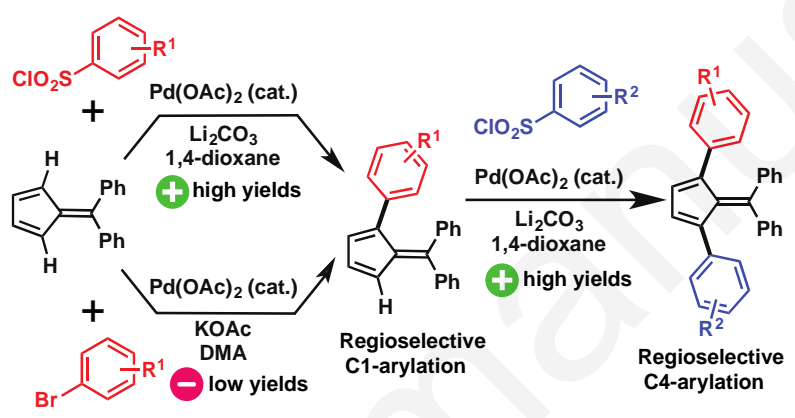

\begin{abstract}
Conditions allowing the palladium-catalysed regioselective direct arylation of fulvene derivatives are reported. The nature of the aryl source exhibits an important influence on the yield. The reaction of fulvenes with aryl bromides gave poor yields; whereas, the use of benzenesulfonyl chlorides gave rise to fulvenes arylated at $\mathrm{C} 1$ - and C4-positions on the 5-membered ring in good yields. The reaction tolerates various substituents such as nitrile, nitro, fluoro, trifluoromethyl, chloro or even bromo on the benzenesulfonyl chloride.
\end{abstract}

Fulvenes (Fig. 1) are on the borderline between true aromatic compounds and conjugated dienes, and exhibit high polar character and charge transfer properties. ${ }^{1}$ Some fulvene derivatives also display important biological properties such as Iorfulvene, which is currently evaluated against castrationresistant prostate cancer. ${ }^{2 a}$ They also exhibit important photophysical properties with possible photovoltaic applications. ${ }^{2 \mathrm{~b}, 2 \mathrm{c}}$ Fulvenes are also commonly employed as ligands in organometallic chemistry. ${ }^{2 \mathrm{~d}}$ As a result, there is a continuing interest in the development of versatile methods to access substituted fulvenes.

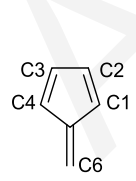

Fulvene

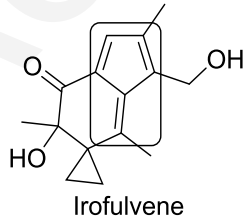

Irofulvene
Figure 1. Structure of fulvene and an example of bioactive fulvene derivative

As most commercially available fulvenes such as 6,6diphenylfulvene do not present any reactive functional groups, their modification requires the activation of $\mathrm{C}-\mathrm{H}$ bonds. The $\mathrm{Pd}$-catalysed direct arylation or vinylation of (hetero)aromatics has recently emerged as a very powerful method for the prepa- ration of substituted (hetero)aromatics. ${ }^{3,4}$ However, there are still important limitations for these $\mathrm{C}-\mathrm{H}$ bond functionalization reactions in terms of regioselectivity and substrate scope. To our knowledge, the $\mathrm{Pd}$-catalysed $\mathrm{C}-\mathrm{H}$ bond functionalization of fulvenes has not been described so far. Moreover, very few methods allowing the synthesis of $\mathrm{C} 1$-arylated fulvenes have been reported. ${ }^{5}$ In 1999, Hong et al. described the reaction of 6-(dimethylamino)fulvene with benzoquinones to prepare hetero $[6+3]$ cycloaddition adducts in good yields (Scheme 1, a). ${ }^{5 \mathrm{a}}$ The reaction of 1,3-diphenyl-1,3-cyclopentadiene with aldehydes affords 1,3-diphenylfulvene derivatives (Scheme 1, b). ${ }^{5 \mathrm{~b}}$ With this method, no functionalized aryl substituents were employed. A few methods for the preparation of C2arylated fulvenes have also been reported. ${ }^{6}$ In 2002, Casez et al. described the dehydration of a cyclopentenol to afford (3cyclohexylidenecyclopenta-1,4-dien-1-yl)benzene in $48 \%$ yield (Scheme 1, c) ${ }^{6}{ }^{6}$ Recently, the preparation of a few other 2,3-diarylfulvene derivatives has been reported by Nair el al. from 1,6-diarylhexa-1,5-diene-3,4-diones using a $\mathrm{N}$ heterocyclic carbene as organocatalyst (Scheme 1,d). ${ }^{6 \mathrm{~d}}$ 
Scheme 1. Access to arylated fulvenes.

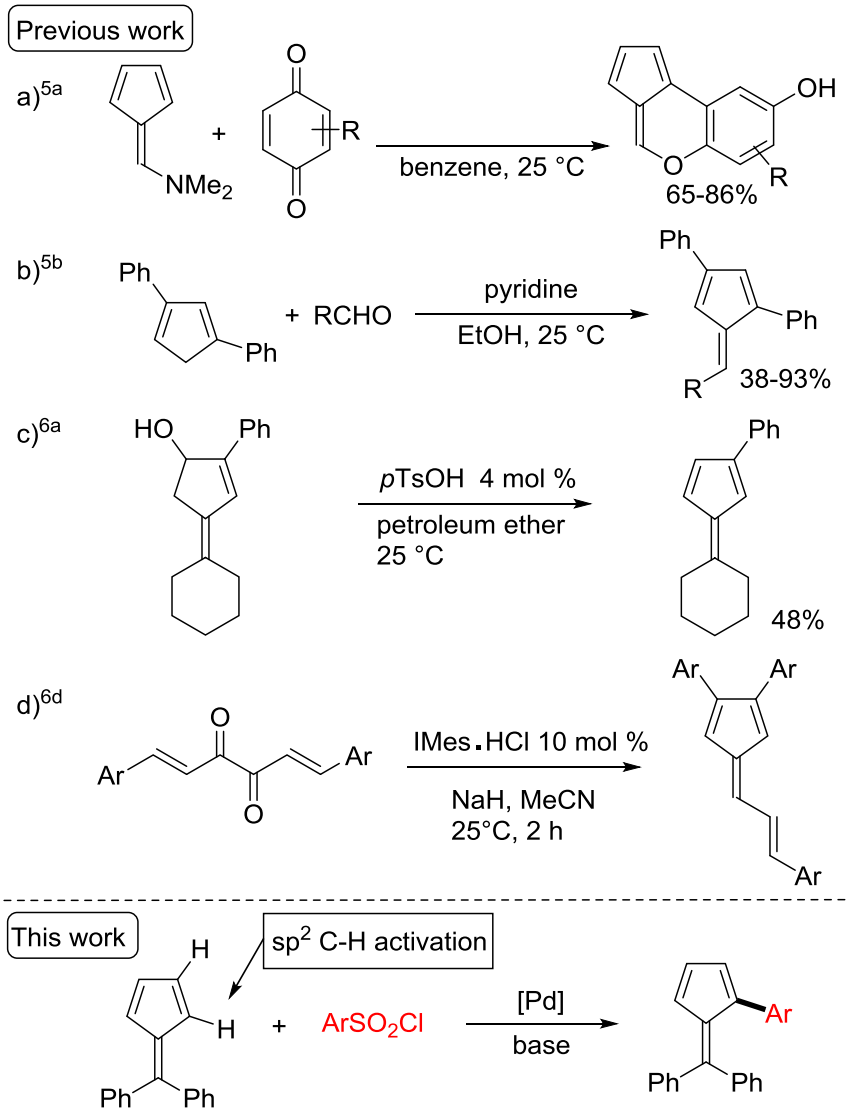

The Pd-catalysed direct arylation of fulvenes would allow the preparation of arylated fulvenes in only one step, without prefunctionalisation of the fulvene moiety, which represents a considerable advantage (Scheme 1, bottom). In addition, such couplings are expected to tolerate a variety of useful functional groups on arenes, which would allow a straightforward modification of the aryl substituents and hence of the properties of the resulting fulvene derivatives. Therefore, reactivity of fulvenes in Pd-catalysed direct arylation needed to be investigated.

We now (i) report on the influence of the reaction conditions and aryl source in the Pd-catalysed direct arylation of 6,6-diphenylfulvene, and (ii) show the scope of the $\mathrm{sp}^{2}$ functionalization of 6,6-diphenylfulvene.

Using conditions employed for the direct arylation of various heteroaromatics in our previous works, ${ }^{7}$ we initially examined the influence of the nature of base and catalyst for the coupling of 1.5 equiv of 6,6-diphenylfulvene with 1 equiv of 4-bromonitrobenzene using DMA as the solvent (Table 1). The use of KOAc as base and $5 \mathrm{~mol} \% \mathrm{Pd}(\mathrm{OAc})_{2}$ as catalyst resulted in the regioselective formation of product 1a (arylation at $\mathrm{C} 1$-position on the 5-membered ring, see Fig. 1) but in low yield; whereas, the use of $\operatorname{PdCl}\left(\mathrm{C}_{3} \mathrm{H}_{5}\right)(\mathrm{dppb})$ catalyst gave no product (Table 1, entries 1 and 2). The use of CsOAc, $\mathrm{NaOAc}$ or $\mathrm{Li}_{2} \mathrm{CO}_{3}$ as bases did not allow to improve the yield in 1a (Table 1, entries 3-5). Benzenesulfonyl chlorides represent useful alternative coupling partners to aryl halides in palladium-catalysed direct arylations. ${ }^{8-12}$ Their use, instead of aryl halides, drastically modify the reaction outcome of some direct arylations due to a change in the catalytic cycle. ${ }^{12 a}$ Moreover, the use of benzenesulfonyl chloride as aryl source is very attractive as the reactions performed with such substrates tolerates a variety of substituents. ${ }^{12 \mathrm{~d}}$

Table 1. Influence of the reaction conditions for palladiumcatalysed direct coupling of 6,6-diphenylfulvene with nitrobenzene derivatives.

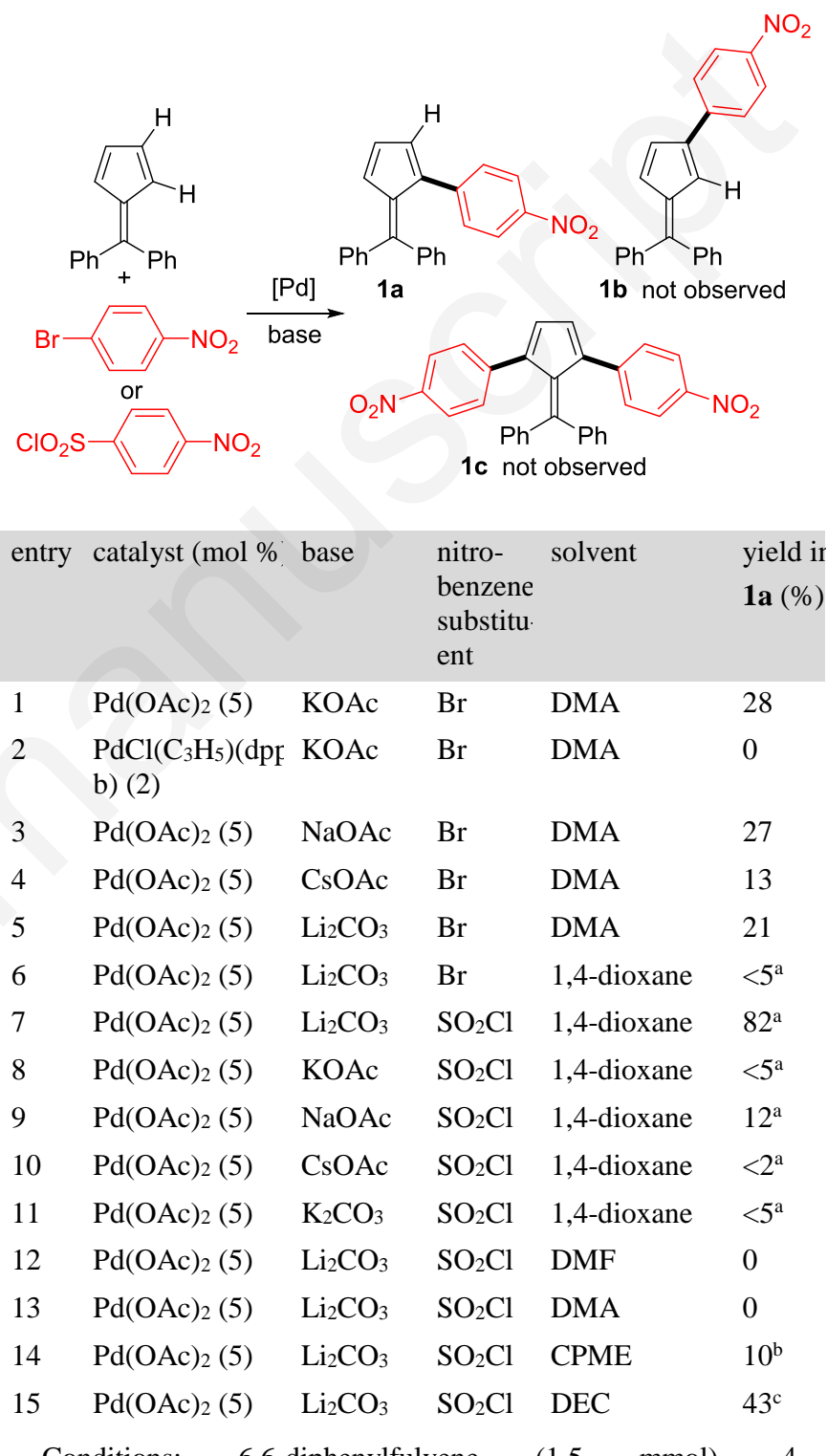

Conditions: 6,6-diphenylfulvene $\quad(1.5 \quad \mathrm{mmol})$, 4bromonitrobenzene or 4-nitrobenzenesulfonyl chloride (1 mmol), base $(2 \mathrm{mmol})$, under argon, $4 \mathrm{~h}, 150{ }^{\circ} \mathrm{C}$, GC and NMR conversions, isolated yields. ${ }^{\mathrm{a}} 140{ }^{\circ} \mathrm{C}$. ${ }^{\mathrm{b}}$ In CPME (cyclopentyl methyl ether) at $110^{\circ} \mathrm{C} .{ }^{\mathrm{c}}$ In DEC (diethyl carbonate) at $130{ }^{\circ} \mathrm{C}$.

Based on our previous results on Pd-catalysed desulfitative coupling with heteroarene derivatives, ${ }^{12}$ we first examined the reaction outcome using 1.5 equiv of 6,6-diphenylfulvene with 1 equiv of 4-nitrobenzenesulfonyl chloride in the presence of 5 
mol \% $\mathrm{Pd}(\mathrm{OAc})_{2}$ catalyst and $\mathrm{Li}_{2} \mathrm{CO}_{3}$ as the base at $140{ }^{\circ} \mathrm{C}$. Under these conditions, the regioselective formation of $\mathbf{1 a}$ in $82 \%$ yield was obtained; whereas, no formation of $\mathbf{1 b}$ or diarylation product 1c was detected by GC/MS analysis of the crude mixture (Table 1, entry 7). The use of KOAc, NaOAc, CsOAc or $\mathrm{K}_{2} \mathrm{CO}_{3}$ as bases led to very low yields in 1a showing the crucial role of the base in such desulfitative couplings (Table 1, entries 8-11). Reactions performed in DMF or DMA gave no product; whereas cyclopentyl methyl ether and diethyl carbonate afforded 1a in low yields (Table 1, entries 12-15). Finally, we also studied the reactivity of benzenesulfinic acid sodium salt as the coupling partner instead of 4nitrobenzenesulfonyl chloride under the same reaction conditions. However, no formation of coupling product was detected by GC-MS analysis of the crude mixture.

Using $5 \mathrm{~mol} \% \mathrm{Pd}(\mathrm{OAc})_{2}$ catalyst, $\mathrm{Li}_{2} \mathrm{CO}_{3}$ base in 1,4dioxane, the scope of the $\mathrm{C} 1$-arylation of 6,6-diphenylfulvene with various benzenesulfonyl chlorides was investigated (Scheme 2). Moderate yields of 54\% and 52\% in $\mathbf{2}$ and $\mathbf{3}$ were obtained by coupling of 6,6-diphenylfulvene with benzenesulfonyl chlorides bearing fluoro or methyl para-substituents. Products $\mathbf{2}$ and $\mathbf{3}$ were only observed in trace amount when aryl bromides were employed as aryl source; whereas, from the more electron deficient 4-bromobenzonitrile and 6,6diphenylfulvene, the desired product $\mathbf{4}$ was obtained in $38 \%$ yield. The higher yields in $\mathbf{1 a}$ and $\mathbf{4}$ obtained with electron deficient aryl bromides might come from their easier oxidative addition to palladium. Then, we examined the reactivity of a few ortho-substituted benzenesulfonyl chlorides. Good yields of $62 \%$ and $61 \%$ in $\mathbf{5}$ and $\mathbf{6}$ were obtained from 2-chloro- and 2-cyano-substituted benzenesulfonyl chlorides. From 2nitrobenzenesulfonyl chloride and 6,6-diphenylfulvene, product 7 was only obtained in $47 \%$ yield due to the formation of some degradation products. The use of 2-bromonitrobenzene as aryl source did not allowed to improve the yield in 7. Benzenesulfonyl chlorides containing two $\mathrm{Cl}, \mathrm{CF}_{3}$, or $\mathrm{NO}_{2}$ substituents also gave the expected 1-arylfulvenes 8-10 in good yields. As the use of $\mathrm{ArSO}_{2} \mathrm{Cl}$ as coupling partners in $\mathrm{Pd}$ catalysed direct arylations tolerates bromo substituents, ${ }^{12 \mathrm{~d}}$ the behaviour of two bromobenzenesulfonyl chlorides for coupling with 6,6-diphenylfulvene was investigated. Reaction performed in the presence of $\mathrm{ArSO}_{2} \mathrm{Cl}$ containing a 2-bromoor 3,4-dibromo-substituents gave $\mathbf{1 1}$ and $\mathbf{1 2}$ in satisfactory yields without cleavage of the $\mathrm{C}-\mathrm{Br}$ bonds, allowing further transformations. Polyfluorinated molecules are ubiquitous in medicinal chemistry, owing to fluorine atom properties which induces a dramatic change in the molecules behaviour. The use of $\mathrm{ArSO}_{2} \mathrm{Cl}$ containing fluorine atoms should offer a straightforward route to polyfluorinated fulvenes. From 2,3,4trifluorobenzenesulfonyl chloride and 6,6-diphenylfulvene, the desired product 13 was obtained in $70 \%$ yield. The regioselectivity of these arylations was unambiguously assigned by X-ray analysis of $\mathbf{1 0}$ (Scheme 2). It should be mentioned that for the reactions with 4-fluoro, 4-methyl- and 2-chlorosubstituted benzenesulfonyl chlorides, low amounts of diarylated fulvenes were detected by GC/MS analysis of the crude mixtures.
Scheme 2. Palladium-catalysed direct C1-arylation of 6,6diphenylfulvene
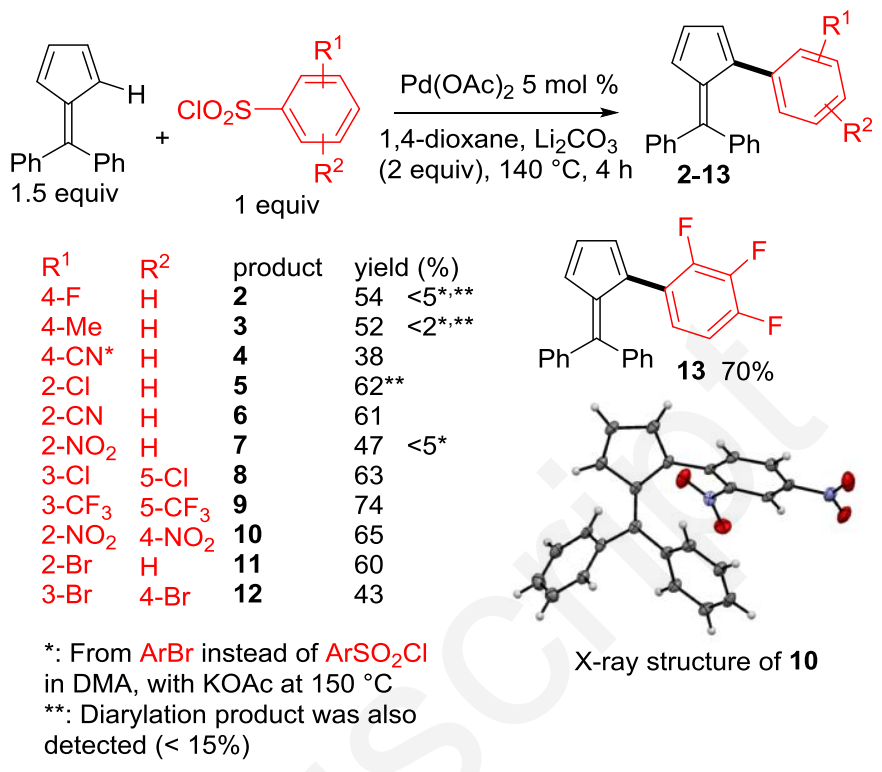

Under the same reaction conditions, but using 3 equiv of benzenesulfonyl chloride derivative, the access to symmetrical 1,4-diarylfulvenes was found to proceed in moderate to good yields (Scheme 3). From 4-chloro- or 3,4-difluoro-substituted benzenesulfonyl chlorides, the 1,4-diarylated fulvenes 14 and 15 were obtained in $62 \%$ and $67 \%$ yields, respectively. The 1,4-diarylated fulvene derivative $\mathbf{1 6}$ was obtained in a slightly lower yield of $60 \%$ from 4-bromobenzenesulfonyl chloride. Again no cleavage of the $\mathrm{C}-\mathrm{Br}$ bonds was observed.

Scheme 3. Palladium-catalysed direct C1,C4-diarylation of 6,6-diphenylfulvene.

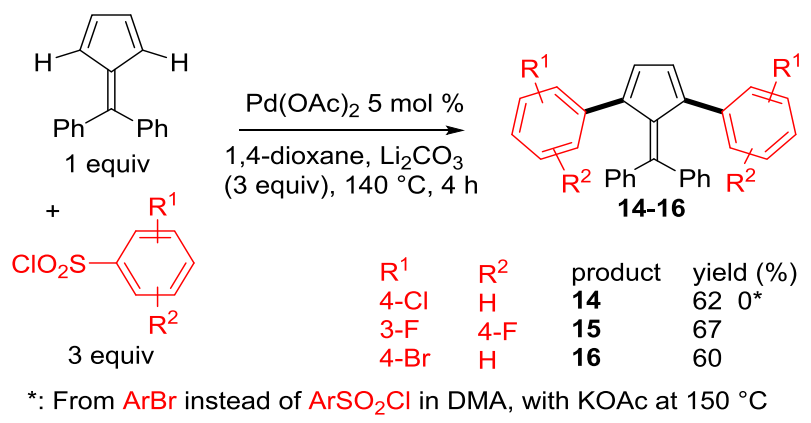

The one pot direct C1,C4-diarylation of 6,6-diphenylfulvene is possible (see scheme 3); however, the major advantage of such direct arylations is to allow the formation of 1,4diarylated fulvenes containing two different aryl groups via successive arylations. Using a set of benzenesulfonyl chlorides and ((2-(4-nitrophenyl)cyclopenta-2,4-dien-1ylidene)methylene)dibenzene 1a, under the same reaction conditions than for the first arylation, the synthesis of such non-symmetrically substituted 1,4-diarylfulvenes was studied (Scheme 4). In all cases, good to high yields in the desired products 17-25 were obtained. The reaction tolerates both electron-withdrawing and electron-donating substituents on the benzenesulfonyl chloride. Moreover, the reaction with 2- 
bromobenzenesulfonyl chloride gave $\mathbf{2 3}$ in $78 \%$ yield, again without cleavage of the $\mathrm{C}$-Br bond.

Scheme 4. Palladium-catalysed direct C4-arylation of C1arylated 6,6-diphenylfulvene $1 \mathrm{a}$.

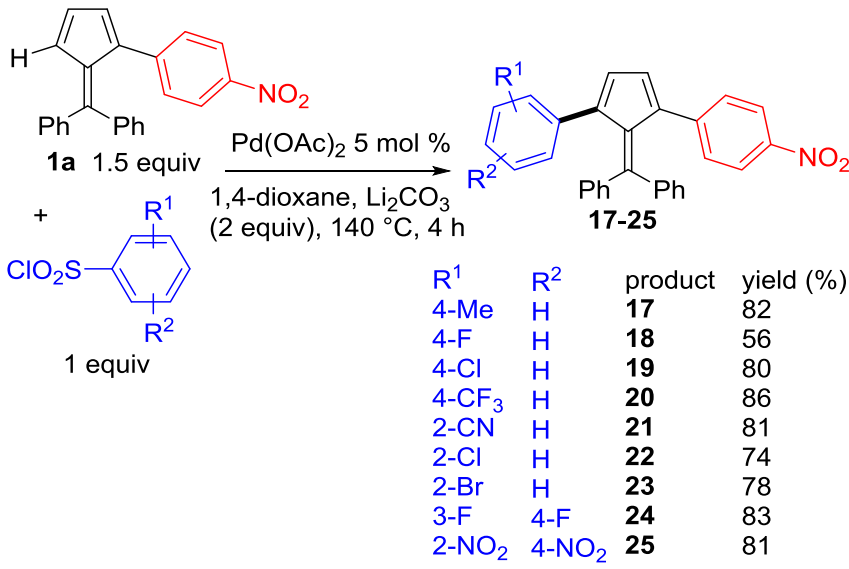

In summary, we have demonstrated that the Pd-catalysed C$\mathrm{H}$ bond functionalisation of fulvenes is possible when appropriate reaction conditions are employed. The reaction of 6,6diphenylfulvene with a set of benzenesulfonyl chlorides in the presence of $\mathrm{Pd}(\mathrm{OAc})_{2}$ catalyst affords regioselectively the $\mathrm{C} 1$ arylated fulvenes. Moreover using an excess of benzenesulfonyl chlorides or from $\mathrm{C} 1$-arylated fulvenes, the formation of $\mathrm{C} 1, \mathrm{C} 4$-diarylated fulvenes also proceed in good yields. The reported conditions offer routes for fast and direct access to arylated fulvene derivatives from commercially available compounds, catalyst and inexpensive base. This protocol is applicable to a range of functions on the benzenesulfonyl chloride, including reactive ones. Such functional group tolerance should allow the easy modification of these products, a strategy enabling the tuning of their properties.

\section{ASSOCIATED CONTENT}

\section{Supporting Information}

Proposed catalytic cycle, experimental procedures, ${ }^{1} \mathrm{H}$ and ${ }^{13} \mathrm{C}$ NMR of all compounds, UV-vis absorption spectra of products $\mathbf{3}$, $9,10,13,14,19,21, X$-ray analysis of 10. The Supporting Information is available free of charge on the ACS Publications website.

\section{AUTHOR INFORMATION}

\section{Corresponding Author}

* E-mail: jean-francois-soule@univ-rennes1.fr; henri.doucet@univ-rennes1.fr

\section{Author Contributions}

The manuscript was written through contributions of all authors. All authors have given approval to the final version of the manuscript.

\section{ACKNOWLEDGMENT}

We thank the "CNRS", "Rennes Metropole", "UTIQUE" and Scientific Ministry of Higher Education Research of Tunisia for providing financial support.

\section{REFERENCES}

1. (a) Bergmann, E. D. Chem. Rev. 1968, 68, 41; (b) Hopf, H.; Sherburn, M. S. Cross Conjugation: Modern Dendralene, Radialene and Fulvene Chemistry, Wiley-VCH, 2016.

2. (a) Butler, M. S. Nat. Prod. Rep. 2008, 25, 475; (b) Peloquin, A. J.; Stone, R. L.; Avila, S. E.; Rudico, E. R.; Horn, C. B.; Gardner, K. A.; Ball, D. W.; Johnson, J. E. B.; Iacono, S. T.; Balaich, G. J. J. Org. Chem. 2012, 77, 6371; (c) Godman, N. P.; Balaich, G. J.; Iacono, S. T. Chem. Commun. 2016, 52, 5242; (d) Kreindlin, A. Z.; Rybinskaya, M. I. Russ. Chem. Rev. 2004, 73, 417.

3. For reviews on metal-catalysed $\mathrm{C}-\mathrm{H}$ bond functionalisation: (a) Alberico, D.; Scott, M. E.; Lautens, M. Chem. Rev. 2007, 107, 174-238; (b) Satoh, T.; Miura, M. Chem. Lett. 2007, 36, 200-205; c) Li, B.-J.; Yang, S.-D.; Shi, Z.-J. Synlett 2008, 949-957; (d) Bellina, F.; Rossi, R. Tetrahedron 2009, 65, 10269-10310; (e) Ackermann, L.; Vicente, R.; Kapdi, A. Angew. Chem. Int. Ed. 2009, 48, 9792-9826; (f) Chen, X.; Engle, K. M.; Wang, D.-H.; Yu, J.-Q. Angew. Chem. Int. Ed. 2009, 48, 5094-5115; (g) Wencel-Delord, J.; Glorius, F. Nature Chem. 2013, 5, 369-375; (h) Rouquet, G.; Chatani, N. Angew. Chem., Int. Ed. 2013, 52, 11726-11743; (i) Rossi, R.; Bellina, F.; Lessi, M.; Manzini, C. Adv. Synth. Catal. 2014, 356, 17-117; (j) Zhang, M.; Zhang, Y.; Jie, X.; Zhao, H.; Li, G.; Su, W. Org. Chem. Front. 2014, 1, $843-$ 895; (k) Bheeter, C. B.; Chen, L.; Soulé, J.-F.; Doucet, H. Cat. Sci. Technol. 2016, 6, 2005-2049.

4. For metal-catalysed functionalization of the 5-membered ring C$\mathrm{H}$ bonds of azulenes or acenaphthylene: (a) Dyker, G. Tetrahedron Lett. 1991, 32, 7241; (b) Dyker, G.; Borowski, S.; Heiermann, J.; Körning, J.; Opwis, K.; Henkel, G.; Köckerling, M. J. Organomet. Chem. 2000, 606, 108; (c) Pletnev, A. A.; Tian, Q.; Larock, R. C. J. Org. Chem. 2002, 67, 9276; (d) Sugihara, T.; Satoh, T.; Miura, M.; Nomura, M. Adv. Synth. Catal. 2004, 346, 1765; (e) Dyker, G.; Merz, K.; Oppel, I. M.; Muth, E. Synlett 2007, 897; (f) Pillekamp, M.; Aniol, A.; Heppekausen, J.; Neukirchen, S.; Seel, S.; Oppel, I. M.; Dyker, G. Synlett 2009, 133; (g) Zhao, L.; Bruneau, C.; Doucet, H. Chem. Commun. 2013, 49, 5598; (h) Murai, M.; Takami, K.; Takeshima, H.; Takai, K. Org. Lett. 2015, 17, 1798; (i) Murai, M.; Yanagawa, M.; Nakamura, M.; Takai, K. Asian J. Org. Chem. 2016, 5, 629.

5. (a) Hong, B.-C.; Sun, H.-I.; Chen, Z.-Y. Chem. Commun. 1999, 2125; (b) Peloquin, A. J.; Stone, R. L.; Avila, S. E.; Rudico, E. R.; Horn, C. B.; Gardner, K. A.; Ball, D. W.; Johnson, J. E. B.; Iacono, S. T.; Balaich, G. J. J. Org. Chem. 2012, 77, 6371.

6. (a) Antras, F.; Ahmar, M.; Cazes, B. Tetrahedron Lett. 2002, 43, 5029; See also (b) Andrew, T. L.; Cox, J. R.; Swager, T. M. Org. Lett. 2010, 12, 5302; (c) Eshdat, L.; Berger, H.; Hopf, H.; Rabinovitz, M. J. Am. Chem. Soc. 2002, 124, 3822; (d) Sinu, C. R.; Suresh, E.; Nair, V. Org. Lett. 2013, 15, 6230.

7. Mohand, A.; Belkessam, F.; Soulé, J.-F.; Doucet, H. ChemCatChem 2016, 8, 1583

8. For a review on transition-metal catalysed desulfitative couplings: Yuan, K.; Soulé, J.-F.; Doucet, H. ACS Catal. 2015, 5, 978.

9. For Heck reaction with benzenesulfonyl chlorides: (a) Miura, M.; Hashimoto, H.; Itoh, K.; Nomura, M. Tetrahedron Lett. 1989, 30, 975; (b) Miura, M.; Hashimoto, H.; Itoh, K.; Nomura, M. J. Chem. Soc., Perkin Trans. 1 1990, 2207; (c) Dubbaka, S. R.; Vogel, P.; Chem. Eur. J. 2005, 11, 2633.

10. (a) Zhao, X.; Dimitrijevic, E.; Dong, V. M. J. Am. Chem. Soc. 2009, 131, 3466; (b) Zhao, X.; Dong, V. M. Angew. Chem., Int. Ed. 2011, 50, 932; (c) Chen, R.; Liu, S.; Liu, X.; Yang, L.; Deng, G.-J. Org. Biomol. Chem. 2011, 9, 7675.

11. For a review on transition-metal mediated C-S bond activation: Wang, L.; He, W.; Yu, Z. Chem. Soc. Rev. 2013, 42, 599.

12. (a) Yuan, K.; Doucet, H. Chem. Sci. 2014, 5, 392; (b) Loukotova, L.; Yuan, K.; Doucet, H. ChemCatChem 2014, 6, 1303; (c) Jin, R.; Yuan, K.; Chatelain, E.; Soulé, J.-F.; Doucet, H. Adv. Synth. Catal. 2014, 356, 3831; (d) Skhiri, A.; Beladhria, A.; Yuan, K.; Soulé, J.-F.; Ben Salem, R.; Doucet, H. Eur. J. Org. Chem. 2015, 4428. 